\title{
Environmental safety as the most important area of ensuring national security and sustainable development of the Russian Federation
}

\author{
Elena Vorontsova $^{1}$, Andrey Vorontsov ${ }^{1}$, and Yuriy Drozdenko ${ }^{2 *}$ \\ ${ }^{1}$ South-West State University, 94, 50 let Oktyabrya street, Kursk, 305040, Russia \\ ${ }^{2}$ T.F. Gorbachev Kuzbass State Technical University, 28, Vesennyaya, Kemerovo, 650000, Russia
}

\begin{abstract}
The article is devoted to the study of problematic issues of ensuring environmental safety in the Russian Federation as an urgent task of the state and society, on the solution of which the national security of the country and the possibility of its sustainable development largely depend. The role and importance of environmental safety in the system of national security of Russia is analyzed, the necessity of forming and implementing a long-term state policy in the field of environmental protection and rational use of natural resources is proved. On the basis of environmental monitoring data, the current state of the environment is characterized, especially in areas of intensive industrial production (the Urals, Siberia, the Arctic), negative anthropogenic factors are identified that violate the ecological balance in the territories of active resource extraction, and the environmental threats arising in this connection are analyzed. It is noted that in the context of increasing economic activity and global climate change, compliance with environmental safety requirements becomes a factor capable of ensuring sustainable economic development.
\end{abstract}

\section{Introduction}

Currently, we are witnessing global climatic, biological and geological (landscape) transformations taking place on the planet and having a significant impact on all aspects of modern human life, regardless of the territory of his residence. Biosphere changes affect all countries and continents, their negative consequences are felt not only by underdeveloped states, but also by states that are usually referred to as "post-industrial", i.e. states with a high level of economic development and advanced technologies. At the same time, it is the industrially developed countries that make the greatest contribution to the process of ongoing natural changes, since it is they who most actively use the resources of the environment, seeking to satisfy the ever-increasing material needs of their population.

For a long time, the processes of self-healing of the biosphere made it possible to compensate for the damage caused by anthropogenic impact. However, over the past few decades, the level of anthropogenic impact has increased so much[1] that the regenerative

* Corresponding author: duv.gmik@,kuzstu.ru 
mechanisms of nature have ceased to cope with this impact, clearly revealing the vulnerability of the biosphere as a single self-regulatory system, of which man is a part. Currently, this manifests itself in the already felt lack of water, food, energy and other natural resources that allow humanity to survive as a biological species. In a number of cases, the lack of these resources leads to armed conflicts between states (recall the recent clash between Kyrgyzstan and Tajikistan over a shortage of water for land reclamation[2], as well as the constant claims of a number of African states against each other, therefore, the same issue[3]). In addition, climate change, a decrease in the area of land suitable for agriculture leads to mass migration of the population, which turns into extremely negative consequences in various regions of the world.

Awareness of the impending ecological catastrophe that could destroy the civilization of "homo sapiens" forced the world community (first of all, the leading countries) to reconsider their approaches to the paradigms of socio-economic development, since the views previously dominant in this area led the human community to a suicidal collision with nature.

The result of rethinking the foundations of the interaction of human society with the environment in the context of understanding that this sphere is the natural environment (and, accordingly, a necessary condition) for the existence of mankind itself, was the promotion of a number of new ideas, which, according to scientists[4], overcome the deepest crisis of modern civilization, which threatens to lead to socio-cultural regression. One of these ideas was the idea of sustainable development, which was perceived by the world community as a new type of worldview based on understanding the relationship between global environmental problems and socio-economic development[5].

In the context of large-scale environmental degradation, ensuring sustainable socioeconomic development is impossible without achieving the required level of environmental safety, which allows carrying out production activities without going beyond the capacity of the biosphere. For the Russian Federation, the task of ensuring environmental safety has long acquired the character of a national project, which is of critical importance not only for Russian society, but also for other countries. This is due to:

- firstly, the interconnectedness of all processes occurring in nature. In this case, due to the vast extent of the territory on which active industrial activity is carried out, due to the world's largest length of the border line with neighboring states, the negative environmental consequences of industrial activity on the territory of Russia have a direct impact on the state of the environment in a number of other states. ... At the same time, there is an active reverse process of moving hazardous production wastes from other states to our territory. Ecosystems do not know state borders, and a change in the natural balance of these systems on the territory of one of the states will almost inevitably entail similar changes on the territory of another;

- secondly, by the fact that in many regions of our country the level of anthropogenic impact has already exceeded its maximum permissible norms, crossing the boundaries of natural capabilities to self-recovery. Chemical pollution of river and sea areas, deforestation and degradation of forests, soil and air pollution - all this poses a real threat to the national security of the Russian Federation, since it directly affects the life support of our society;

- thirdly, at present there is an active industrial development of Russian territories that have a climate-forming importance for the entire globe (Arctic, Siberia). Violation of the ecological balance in these territories can lead to catastrophic consequences on a global scale. At the same time, serious concerns are caused by industrial technologies used to obtain Arctic and Siberian resources. Not all of them meet the criteria of safety for the environment, and, accordingly, for the person himself.

The above circumstances actualize the issues of ensuring environmental safety in the Russian Federation, placing this problem in the category of the primary directions of state 
activities to ensure national security and sustainable development of our country. This is a complex task that requires economic, technological, organizational, managerial and legal measures to be resolved. We will highlight some aspects of the problem of ensuring environmental safety in the Russian Federation in our article.

\section{Methodology}

The breadth and multidimensionality of the topic studied by us led to a complex of scientific methods used to study it. Our work was based on the principles of scientific character, objectivity, consideration of different points of view, dialectical interconnection of the phenomena under study.

The empirical material for the study was the data of environmental monitoring carried out in various regions of the Russian Federation (the data obtained during it were published in the official reports of state bodies, as well as environmental organizations. In addition, we used the data presented in scientific research on this topic).

The analysis covered the content of state programs for sustainable development of the Russian Federation, strategic program documents in the field of national security, environmental safety, legislation in the field of nature protection and resource conservation.

The direct tools of our research were the statistical method, the method of subject comparison, systemic and logical analysis, the formal legal method, and the futurological method.

\section{Results and discussion}

The ecological crisis that has affected most of the planet has also affected Russia. This jeopardizes the possibility of sustainable development of our country, especially since in the Russian Federation there are a number of factors that negatively affect the quality characteristics of the environment necessary for a full and healthy life. In addition to planetary factors that manifest themselves in the overwhelming majority of countries, such as climate change and the associated increase in the number of natural disasters, a decrease in natural resources with a simultaneous tendency to an increase in their consumption, degradation under the influence of anthropogenic impact of the main components of the biosphere, an increase in the risks of industrial activities and environmental damage from man-made disasters, the state of the environment in Russia is seriously affected by domestic factors caused by all the previous socio-economic development of the country. These factors include the traditional for Russia orientation of the national economy towards resource-extracting and resource-intensive industries, insufficient effectiveness of the organizational and managerial (including control and supervisory) functions of the state in the field of environmental protection and, in general, the underdevelopment of legal mechanisms for the use of natural resources and nature protection. (despite the existence of the Forestry, Water and other codes aimed at regulating relations in the field of interaction with the environment), the widespread use of outdated technologies in the resourceextracting industries (oil, gas, mining) and the deterioration of fixed assets, which leads to an increase in the threat of environmental disasters from industrial accidents. To this should be added the low level of ecological culture of the population brought up in the spirit of the anthropocentric concept "man is the king of nature".

At present, the combined effect of the above factors has led to the fact that a significant part of the industrially developed and densely populated territory of the Russian Federation is recognized even in official sources as ecologically unfavorable[6]. All-Russian environmental monitoring data indicate that almost $20 \%$ of the country's urban population 
lives in conditions of high and very high air pollution[6]. In some industrial areas, the concentration of harmful substances in the atmosphere is several times higher than the maximum permissible standards. First of all, this applies to the territories where ore, coal and other minerals are mined by the open method (Kuzbass), a large number of enterprises of the metallurgical, mining and chemical industries operate (especially in the Urals Chelyabinsk, Magnitogorsk, in polar Siberia - Norilsk, on the Kola Peninsula Monchegorsk and other cities).

In the Russian Federation, the discharge of untreated industrial and domestic wastewater is still widely practiced. A huge amount of the most hazardous waste of industrial production and agricultural activities, together with wastewater, gets into the waters of rivers, lakes and even into the seas and oceans. Not only surface water is polluted, but also groundwater. The underdevelopment of modern treatment technologies and the lack of water treatment facilities lead to the fact that almost $40 \%$ of the population of the Russian Federation regularly use water that does not meet sanitary and hygienic requirements[6]. This poses a real threat to the health of citizens, especially in the context of the spread of epidemics of infectious diseases in the modern world.

The ecological situation in the Arctic region of our country is of particular concern. This region plays a key role in maintaining the global functions of the biosphere, while the state of its environment, especially along the coast of the Arctic Ocean, is in some cases catastrophic. Pollution of the coastal areas and the water area of the Arctic Ocean is facilitated by the fact that it is here that the mouths of the most full-flowing rivers of Siberia and the Urals, carrying industrial waste from individually developed regions of Russia, come out[7].

The natural and climatic features of the Arctic zone determine the increased vulnerability of its ecological systems. The slowed down metabolism of natural processes leads to the accumulation of chemical, radiation and other pollutants in the Arctic environment, formed as a result of ill-considered economic activities, as well as nuclear weapons tests, which were actively carried out here during the Cold War.

A similar "accumulated" effect of harmful effects is manifested throughout the territory of the Russian Federation (according to the data contained in the Decree of the President of the Russian Federation of April 19, 2017 "On the strategy of environmental safety of the Russian Federation for the period up to 2025", identified (author's) sources accumulated harm pose a potential threat to life and health for 17 million people)[6], however, in the Arctic zone of our country, the effect of accumulated harm is even more noticeable[8]. To the general picture of the ecological situation in the Russian Arctic, one should add destruction of permafrost, which occurs under the influence of global climatic changes and leads to adverse consequences both for the functioning of the industrial complex and for the life of people and other living organisms.

At the same time, in the Russian Federation, the possibility of sustainable socioeconomic development is associated with the further industrial development of the Arctic region, which has a significant amount of natural resources. This a priori implies an increase in anthropogenic load on these territories, and, accordingly, creates additional risks for the environment (primarily due to the constantly occurring spills of oil and oil products, leading to irreversible consequences for nature). This circumstance, taking into account the above-mentioned vulnerability of the ecological systems of the Arctic territories and their importance for the functioning of the world biosphere, generates a huge contradiction in Russia's plans for its transition to sustainable development, since only safe development can be sustainable. It is appropriate here to cite the opinion of Academician of the Russian Academy of Sciences N.N. Moiseev, who said that "the future of mankind can be guaranteed only in conditions of a more or less stable circulation of substances [9]. At the same time, it should be stated that in many cases humanity has already violated and 
continues to disrupt the natural course of natural biochemical processes, thereby reducing the possibilities for its own development and survival.

In support of our words, it should be noted that in the Russian Federation, as a result of past economic activities, according to official data alone, by 2017, more than 30 billion tons of industrial and domestic waste were accumulated, many of which are not involved in secondary economic circulation (i.e. not processed and placed in open areas). Every year, an average of 4 billion tons of waste is added to them, which has now led to the fact that under the territories of their disposal (dumps) there is 4 million hectares of land, moreover, land that could be used for agricultural use[6]. We add to this that the area of such territories is constantly increasing, which cannot but cause great concern, especially taking into account the tendency in the Russian Federation to a widespread deterioration of the state of the soil cover (note that in Russia more than half of the total area of agricultural land is subject to wind and water erosion, waterlogging, salinization, etc.).

Thus, the general state of the environment in the Russian Federation requires the state and society to take drastic measures aimed at restoring the natural balance of natural resources, which is a condition for the sustainable development of our country in the near and long term. This actualizes the need to ensure environmental safety, the current (current) state of which poses a threat to the national security of the Russian Federation and is an obstacle to the realization of its national interests.

In turn, the implementation of large-scale measures to ensure environmental safety should be preceded by a deep scientific understanding of the entire complex of problems arising in the "man - nature" system. The need for such an understanding is due to the very essence of the concept of sustainable development, which implies economic growth while reducing the anthropogenic load on the environment. Setting itself the task of sustainable social and economic development, the Russian Federation should take into account the shrinking possibilities of the biosphere and be guided by the principle formulated back in 1978 in the World Conservation Strategy: “.... for development to be sustainable, it is necessary to take into account not only its economic aspects, but also social and environmental factors ... "[10]. At the same time, cardinal measures to ensure environmental safety should not turn into a campaign that is characteristic of Russia. A long-term state policy (issued by the author) in the field of environmental protection and rational use of natural resources is required.

It should be noted that, acting within the framework of the Concept of Transition to Sustainable Development[11], the leadership of the Russian state focused its efforts on the formation and subsequent implementation of a long-term (long-term) state policy in the field of ecology. This was facilitated by the obvious awareness of the complexity of the task facing Russian society in overcoming the ecological crisis and restoring natural systems.

The process of organizational and legal registration of the above policy began with the adoption in 2002 of the Environmental Doctrine of the Russian Federation[12]. This was the first strategic document that defined the goals, objectives and principles of a unified state policy in the field of environmental protection and rational use of natural resources. It proclaimed that the preservation of nature and the improvement of the environment are the priority areas of activity of the Russian state and society. In the context of achieving the goals of sustainable development proclaimed in the most important international acts, the Ecological Doctrine of Russia emphasized that the natural environment should be included in the system of socio-economic relations, that the natural environment should be included in the system of socio-economic relations as the most valuable component of the national heritage[12]... In the context of following international recommendations on sustainable development, one should also take into account the position enshrined in the Doctrine on 
the need to interconnect the country's socio-economic development and state environmental policy.

The main directions of the state policy in the field of ecology in this document were named as follows: ensuring sustainable use of natural resources; reduction of environmental pollution and resource conservation; preservation and restoration of the natural environment; It should be noted that environmental safety is singled out in the Environmental Doctrine of the Russian Federation as a separate area of state activity, the main tasks of which are to ensure environmental safety of potentially hazardous industrial activities, to rehabilitate territories and water areas affected by technogenic impact on the environment; improving the quality of life and health of the population by improving the ecological indicators of the environment; control over the import, use and distribution of alien species and genetically modified organisms on the territory of the Russian Federation and other tasks. At the same time, the very definition of the concept of "environmental safety" was not contained in the Doctrine, which indicates the insufficient formation of the legal categorical apparatus in this area at that time and the underestimation of its role for the needs of law enforcement.

At the same time, the need for modernization and innovative development of the Russian economy (for the purposes of sustainable existence) made us further consider the problem of ensuring environmental safety as the main component of state policy in the field of ecology. That is, the concept of "ensuring environmental safety" has actually become synonymous with such concepts as "environmental development", "state environmental policy" and some others. Accordingly, the concept of "state of environmental safety" began to be perceived as a synonym for the concept of "state of the environment". This is confirmed by the program documents of the Russian state, which entered into force some time after the adoption of the Environmental Doctrine of the Russian Federation.

The first such document was the Fundamentals of State Policy in the Field of Environmental Development of the Russian Federation for the Period up to 2030[13]. The development of these Fundamentals was caused by the need to ensure the country's environmental safety in the context of increasing industrial activities that ensure socioeconomic growth. However, the speech in the Fundamentals is initially about environmentally oriented (ed.) Economic growth, which predetermines the principles in accordance with which these Fundamentals are implemented: observance of the human right to a favorable environment (this right is enshrined in the Constitution of the Russian Federation and is one of the fundamental social and economic rights of citizens), ensuring favorable conditions for human life (which, in turn, is not possible without ensuring a favorable environment and environmental safety), protection, reproduction and rational use of natural resources (as a condition for ensuring environmental safety and sustainable development), the presumption of environmental the dangers of the planned economic activity (as a result of rethinking the consumer attitude to nature), full compensation for harm caused to the environment and other principles.

The adoption of the Fundamentals was essential for the subsequent development of an organizational and legal mechanism for ensuring environmental safety in the Russian Federation, since the Fundamentals for the first time contained a detailed list of mechanisms for implementing state policy in the field of environmental development. At the same time, one cannot fail to note the conspicuous uncertainty in the formulation of the strategic goal of this policy, which puts the provision of environmental safety in the last place and conceptually separates it from the tasks of preserving a favorable environment, biological diversity of natural resources, which in turn are essential components of environmental safety. ... In this regard, we have a question: what did the authors of the Fundamentals mean by the concept of environmental safety (which is not defined in the document) outside the context of preserving a favorable environment, natural resources and 
biodiversity. And the second question, which naturally arises from the analysis of the text of the Fundamentals: if the document itself states that "the development of these Fundamentals is due to the need to ensure environmental safety" (clause 4, Section 1 General Provisions), then why is the strategic goal of the state policy in the field of environmental development, regulated by the Fundamentals, is formulated not as "ensuring environmental safety", but through listing a wide range of other tasks.

Such legal nuances are characteristic of Russian environmental legislation, which reduces the effectiveness of its operation and does not contribute to the implementation of a long-term state policy to ensure environmental safety. At the same time, its importance for ensuring the national security of the country is so great that it prompts the Russian legislator and the leadership of the Russian state to constantly improve the mechanisms for ensuring it.

To understand the role and significance of the environmental safety of the Russian Federation for the period up to 2025[6]. This strategic document clearly defines that the environmental security of the Russian Federation is an integral part of national security (in addition, in the National Security Strategy, environmental security is named as one of the types of security, along with military, economic, etc.). According to its legal status, the Environmental Security Strategy is a "strategic planning document in the field of ensuring the national (author's) security of the Russian Federation"[6], which indicates that the organizational and legal mechanism for ensuring environmental safety is structurally part of a single mechanism (system) of ensuring national security in general.

The adoption of the Strategy makes it possible to speak about the formation in the Russian Federation of a state policy in the field of ensuring environmental safety. It is environmental safety that becomes a priority of state activity in the implementation of various types of environmental protection measures, the introduction of technologies for rational use of natural resources and other measures aimed at improving the quality of the environment.

In contrast to the previously adopted policy documents - the Environmental Doctrine of the Russian Federation, the Fundamentals of State Policy in the Field of Environmental Development, etc., the Strategy more specifically defines the sphere of state policy aimed at preserving and restoring the natural environment in the face of increasing economic activity and global climate change. Now the long-term state policy, which we are talking about, is officially defined as "state policy in the field of ensuring environmental safety", which is a more specific expression in comparison with the previously used concepts of "state policy in the field of ecology", "state policy in the field of environmental development " and etc.

According to the Strategy, the main mechanisms for the implementation of state policy in the field of environmental safety are: the creation of an environmental monitoring system, informing the population about hazardous hydrometeorological and other natural phenomena, the state of the environment and levels of its pollution, the introduction of integrated environmental permits for environmentally hazardous industries using the best available technologies and a number of others. In addition, the creation and development of a system of environmental funds was declared one of the priority directions in the field of ensuring environmental safety, which indicates the adoption of positive foreign experience in the protection and reproduction of the environment.

In general, it can be stated that in the Russian Federation, environmental safety is viewed as the most important area of ensuring national security and sustainable development of the country. 


\section{Conclusion}

Based on the results of the study, the following conclusions can be drawn:

- the state of the environment in the Russian Federation is a serious problem for the state and society, being a factor that negatively affects the prospects for the country's socioeconomic development, health and quality of life of the population. This makes the task of ensuring environmental safety urgent, compliance with the requirements of which in the context of increasing economic activity and global climatic changes becomes a factor capable of ensuring sustainable economic growth. Thus, for the Russian Federation, ensuring environmental safety is becoming an important area of state activity, on which its national security and sustainable development depend;

- realizing the impossibility of further innovative development of its economy and raising the standard of living of the population in conditions of environmental degradation, the Russian Federation began to form and implement a long-term state policy in the field of environmental protection and rational use of natural resources (state policy in the field of ensuring environmental safety), which has found its way legal expression in a number of strategic program documents, such as the Environmental Doctrine of the Russian Federation, the Fundamentals of State Policy in the Field of Environmental Development, the Environmental Security Strategy of the Russian Federation for the period up to 2025, etc. These documents outline the main conclusions and threats to environmental safety, define goals, tasks, principles and mechanisms for the implementation of long-term state policy aimed at ensuring environmental safety and sustainable development of our country.

In combination with federal laws regulating relations in the field of environmental protection and related industries, this set of legal acts created the necessary organizational and managerial basis for further state activities in the field of environmental safety. At the same time, both the program documents of the Russian state and the current legislation in the field of environmental protection and rational use of natural resources are not devoid of legal shortcomings, which creates problems in practical activities for the implementation of state policy in the field of environmental safety;

- in our opinion, the current mechanisms for the implementation of state policy in the field of ensuring environmental safety do not sufficiently take into account the specifics of especially vulnerable natural areas (the Arctic, some regions of Siberia and the Far East, etc.). in this regard, the Russian legislator needs to step up work in this direction. In addition, it is necessary to expand the system of regional environmental development programs, especially in areas exposed to increased anthropogenic and technogenic pressure.

\section{References}

1. S.A. Pegov, Proceedings of the Institute for System Analysis of the Russian Academy of Sciences, 42, 5 (2009)

2. On the verge of water. What is behind the conflict between Kyrgyzstan and Tajikistan, URL: https://tass.ru/mezhdunarodnaya-panorama/11287787

3. The dispute between Egypt and Ethiopia over the water of the Nile threatens the whole of Europe, URL: https://rg.ru/2020/06/16/spor-egipta-i-efiopii-za-vodu-nilaugrozhaet-vsej-evrope.html

4. Yu.G. Shpakovsky, Bulletin of the University named after O.E. Kutafina 1(17) 38 (2016)

5. O. Turchenko. Sciences of Europe 19-2(19), 29 (2017) 
6. Decree of the President of the Russian Federation dated April 19, 2017 No 176 «On the Strategy of Environmental Safety of the Russian Federation for the Period up to 2025», 17, 2546 (2017)

7. E.V. Vorontsova, A.L. Vorontsov, E3S Web of Conferences ICEPP (2020)

8. E.V. Vorontsova, A.L Vorontsov, Yakut medical journal 3, 80 (2019)

9. N. Moiseyev, To be or not to be ...... To mankind? (GUP IPK Ulyanovsk printing house, Moscow, 1989)

10. Caring for the Earth. Sustainable living strategy. Summary. IUCN / UNEP / WWF. Glad, Switzerland, 24 (1991)

11. Decree of the President of the Russian Federation dated 01.04.1996 3440 «On the Concept of the transition of the Russian Federation to sustainable development», Collected Legislation of the Russian Federation, 15, 1572 (1996)

12. Order of the Government of the Russian Federation of August 31, 2002 No 1225-r «Environmental doctrine of the Russian Federation», Collected Legislation of the Russian Federation, 36, 3510 (2002)

13. Fundamentals of state policy in the field of environmental development of the Russian Federation for the period up to 2030 (approved by the President of the Russian Federation on April 30, 2012) 